\title{
AQUISIÇÃO DO RÓTICO RETROFLEXO DO INGLÊS: INSTRUC̣ÃO EXPLÍCITA POR MEIO DE ULTRASSONOGRAFIA ${ }^{48}$
}

\author{
Giovana Ferreira-Gonçalves ${ }^{49}$ \\ Otávio Tadeu Alves Pereira ${ }^{50}$ \\ Misael Krüger Lemes ${ }^{51}$
}

RESUMO: O presente trabalho busca analisar a aplicação da ultrassonografia como técnica de instrução explícita no processo de aquisição do segmento rótico retroflexo por duas estudantes de nível básico e de nível avançado de inglês como língua estrangeira. Primeiramente, foi realizado um pré-teste (coletas acústicas e articulatórias), o qual serviu de base para comparações dos avanços na produção do segmento retroflexo no transcorrer das etapas de instrução explícita. Logo após, em duas semanas consecutivas, foram realizadas duas sessões de instrução explícita com o auxílio de um professor de inglês e, ao final de cada sessão, coletas pós-teste, as quais foram comparadas à coleta do pré-teste. As coletas incluíram a leitura de nove vocábulos cinco do inglês e quatro do português -, inseridas em frases-veículo e repetidas cinco vezes a cada coleta, nas quais o rótico se encontrava em posições silábicas distintas. As coletas foram feitas dentro de uma cabine acústica, com o auxílio de um aparelho de ultrassom, modelo Mindray DP 6600. Os softwares Praat e Articulate Assistant Advanced foram utilizados para a análise dos dados obtidos. Os resultados encontrados apontaram um avanço significativo na produção do rótico retroflexo em todos os

${ }^{48}$ Pesquisa financiada pelo Conselho Nacional de Desenvolvimento em Pesquisa, processo n. 312273-2015-0.

49 Professora Associada da Universidade Federal de Pelotas. Bolsista de Produtividade do CNPq.

${ }^{50}$ Mestrando na Universidade Estadual de Campinas. Graduado em Licenciatura em Letras, Português/Inglês, pela Universidade Federal de Pelotas. Bolsista CAPES.

51 Mestrando na Universidade Federal de Pelotas. Graduado em Licenciatura em Letras, Português/Inglês, pela Universidade Federal de Pelotas. Bolsista CAPES. 
contextos analisados, o que, sem dúvida, constitui-se em resultado promissor acerca da relevância do uso do ultrassom como ferramenta metodológica na aquisição do segmento retroflexo do inglês por falantes de português.

Palavras-chave: Aquisição fonético-fonológica; Ultrassonografia aplicada ao ensino de línguas; Instrução explícita.

ABSTRACT: The present work seeks to analyze the application of ultrasound as a technique of explicit instruction and therefore examine the acquisition of the retroflex rhotic segment by two learners - a basic and an advanced level - of English as a foreign language. Initially, a pretest involving the collection of acoustic and articulatory data was conducted, which served as a basis for comparing advances in the production of the retroflex in the succession of explicit instruction steps. Afterwards, in two consecutive weeks, an English teacher led two sessions of explicit instruction. At the end of each session, post-test data were collected and compared to pre-test data. The data collection consisted in the reading of nine words - five in English, four in Portuguese -, in which the rhotic emerged in distinct syllabic positions (initial and medial onset, complex onset, medial and final coda). The words were inserted in carrier phrases and repeated five times in each session of data collection. Data were collected using an ultrasound device - Mindray DP 6600 - and recorded inside an acoustic booth. Specific pieces of software such as Praat and Articulate Assistant Advanced (AAA) were used for further analysis. The results indicated an expressive advance in the production of the retroflex rhotic in all contexts analyzed, which undoubtedly evidences the relevance of such methodological tool in the acquisition of the retroflex segment of English as a foreign language.

Keywords: Phonetic and phonological acquisition; Ultrasound applied to language teaching; Explicit instruction.

\section{Introdução}

Este trabalho pretende avaliar a eficácia de sessões de instrução explícita, com base na ultrassonografía, para a aquisição do rótico retroflexo por parte da aprendiz de nível básico em inglês como segunda língua (L2). Busca também analisar e comparar dados acústicos e articulatórios referentes à produção dos róticos do inglês em contextos 
silábicos específicos a partir da produção de duas informantes brasileiras em diferentes níveis de proficiência na língua inglesa.

Parte integrante do projeto "A ultrassonografia e o ensino de línguas”, desenvolvido no Laboratório Emergência da Linguagem Oral (LELO), situado na Universidade Federal de Pelotas, este trabalho, contribui para uma melhor descrição acústico-articulatória dos segmentos róticos, em especial a variante retroflexa, e estabele avanços em relação às técnicas e metodologias para o desenvolvimento de atividades de instrução explícita inovadoras no Brasil e ainda pouco desenvolvidas em outros países.

Os dados foram coletados mediante gravação de aúdio, em aparelho digital, e mediante gravação visual, utilizando imagens ultrassonográficas. Deste modo, os mesmos dados foram avaliados tanto acústica quanto articulatoriamente em softwares específicos para tais análises.

O uso da ultrassonografia para análise articulatória é ainda incipiente no Brasil (FERREIRA-GONÇALVES \& BRUM-DE-PAULA, 2013). Observa-se uma escassez bibliográfica acerca do tema ${ }^{52}$, bem como a militância de questões básicas que impedem a difusão desse tipo de análise lingüística como: (i) o acesso aos aparelhos, de ultrassom já que o custo dos equipamentos ainda é elevado - mesmo considerando o avanço da tecnologia na área -, e o fato de ainda haver poucos pesquisadores no país instrumentalizados para lidarem com tal tecnologia.

Já a instrução explícita, por sua vez, é campo consideravelmente mais desenvolvido dentro da Linguística como um todo, sendo aplicada como ferramenta importante na aquisição do inglês como língua estrangeira por aprendizes brasileiros (ALVES, 2004; MACEDO, 2011; PEROZZO, 2013). Nesse sentido, a utilização da ultrassonografia como técnica de instrução explícita pode viabilizar a conscientização do aprendiz acerca dos gestos articulatórios efetivamente necessários à produção de um determinado segmento.

No presente trabalho, as técnicas de instrução explícita, utilizadas no processo de ensino/aprendizagem do rótico retroflexo do inglês, mostraram-se bastante positivas, pois o aprendiz apresentou melhora

${ }^{52}$ Sobre o emprego do ultrassom na aquisição de línguas estrangeiras por aprendizes brasileiros, ver Cavalheiro (2016), Teixeira (2017) e Teixeira, Ferreira-Gonçalves e Brum-de-Paula (2017). 
significativa na produção do segmento retroflexo em todos os contextos sonoros investigados.

Outro ponto a ser destacado é que a utilização desse tipo de técnica garante uma proximidade entre o aprendiz e sua produção em tempo real, o que possibilita ao estudante uma nova interação com os mecanismos da fala, os quais, muitas vezes, parecem-lhe distantes e abstratos.

\section{Referencial teórico}

A presente sessão tem por objetivo apresentar um panorama acerca da aplicação do ultrassom voltado a pesquisas em aquisição ${ }^{53}$ de segunda língua, doravante L2, subdividindo-se em três tópicos: (i) noções teóricas relativas ao ensino de pronúncia por meio de instrução explícita; (ii) características do ultrassom e seus benefícios aos estudos da linguagem; (iii) aplicabilidade da ferramenta à aquisição de pronúncia de L2.

Sabe-se que a pronúncia de uma L2 é uma das habilidades mais desafiadoras para aprendizes em idade adulta (ABEL et al., 2015). Na esfera atual, o ensino de L2 tem sido conduzido predominantemente pela chamada abordagem comunicativa. No entanto, como professores podem melhorar a pronúncia de falantes ininteligíveis de inglês de forma que se tornem inteligíveis? "Esse é um problema para o ensino de língua comunicativo, uma vez que a maior parte dos proponentes dessa abordagem não tem lidado adequadamente com o papel da pronúncia no ensino de línguas, nem desenvolveu, em acordo, um conjunto de estratégias para ensiná-la de forma comunicativa." (CELCE-MURCIA et al., 2010, p. 9).

Apesar de a abordagem comunicativa não tomar o ensino da pronúncia como um dos pontos de maior proeminência, a importância do papel da instrução explícita na aquisição de L2 tem gradualmente sido reconhecida e investigada, como nos trabalhos de ALVES (2004); LOOSE, (2006) e PEROZZO (2013). Entende-se, por instrução explícita, "todo o procedimento pedagógico tomado pelo professor visando a chamar a atenção, ressaltar ou revisar aspectos da língua-alvo que podem passar despercebidos pelo aprendiz" (ZIMMER; ALVES, 2006).

${ }^{53}$ Nesse trabalho não será feita distinção entre os termos aquisição e aprendizagem. 
Dessa forma, defende-se a importância da instrução explícita, especialmente pelo fato de que, usualmente, a pronúncia é ensinada por meio de técnicas de repetição e/ou imitação. Todavia, "os aprendizes nem sempre são capazes de acompanhar corretamente instruções verbais dadas pelo professor com relação a onde e como movimentar sua língua" (Wilson, 2014).

Nesse sentido, surge a necessidade de serem repensadas as estratégias para se ensinar a pronúncia. A aplicação de artefatos tecnológicos emerge como potencial subsídio aos referidos obstáculos. Dados os avanços tecnológicos, os aparelhos de ultrassom têm se tornado eficientes e seguros, sendo, em termos de custos, bem mais acessíveis que outros instrumentos de captação de imagens, tais como a ressonância magnética ou a eletropalatografia, por exemplo. Ademais, por se tratar de um método não invasivo, no sentido de que não há inserção de qualquer objeto no trato vocal, a produção da fala não sofre alteração quando o ultrassom é empregado (FERREIRA-GONÇALVES; BRUM-DE-PAULA, 2013).

Conforme reportado pela literatura, são muitas as vantagens proporcionadas pelo ultrassom à aquisição de L2. De acordo com Wilson e Gick (2006), um dos benefícios do aparelho ao aprendiz é a possibilidade de "visualizar diretamente os movimentos dos articuladores, o que lhe permitirá uma melhor percepção quanto aos ajustes necessários à sua pronúncia". Nesse sentido, "a aquisição de novos sons da fala é uma experiência multimodal: os aprendizes utilizam não somente informações auditivas, mas também visuais para adquirir os sons e padrões da fala em uma nova língua". (BLISS et al, 2017).

A aplicação da ultrassonografia, em atividades de instrução explícita, tem o potencial de contribuir com o ensino de pronúncia, permitindo "que os alunos visualizem em tempo real imagens de suas línguas enquanto produzem sons individuais" (GICK et al., 2008).

Wilson e Gick (2006) pontuam que, por meio da aplicação da ferramenta, é possível "observar simultaneamente movimentos anteriores e posteriores de língua", o que facilita a produção e percepção de segmentos complexos. Um dos pares de sons do inglês norte americano apontados por Wilson (2014) são a líquida lateral e o rótico retroflexo. Esses sons são considerados complexos por envolverem mais de um gesto articulatório em suas produções. No caso do retroflexo, por exemplo, "três gestos são envolvidos (elevação de ponta/lâmina de língua, retração 
da raiz e arredondamento dos lábios)" (WILSON, 2014). Levando-se em conta a multiplicidade de gestos de língua inerentes à produção desses sons, acredita-se que o feedback visual possa acelerar o processo de aquisição, dada a importância do input visual.

A partir de um estudo piloto realizado por Gick et al. (2008), a aplicação do ultrassom em aquisição de sons da L2 começa gradativamente a ganhar visibilidade e a se tornar objeto de investigação em pesquisas científicas. No âmbito da pesquisa brasileira, a utilização do ultrassom em estudos de L2 ainda é um tema pouco explorado, e o número de trabalhos que o aborda é limitado (DIAS-CAVALHEIRO, 2016; TEIXEIRA-CORRÊA, 2017; TEIXEIRA-CORRÊA; FERREIRAGONÇALVES; BRUM-DE-PAULA, 2017; LEMES; DUARTE; FERREIRA-GONÇALVES, 2018; GARCIA; FERREIRA-GONÇALVES, 2019).

Quanto ao estudo de GICK et al (2008), os autores conduziram uma sessão de treinamento - com duração de uma hora - com três indivíduos japoneses, estudantes de Linguística, tendo como ponto central de investigação os segmentos $/ \mathrm{l} / \mathrm{e} / \mathrm{I} /$. Ao final da sessão, todos os participantes foram capazes de produzir com sucesso os segmentos alvos. Cabe ressaltar, no entanto, que o trabalho mencionado não observou se os efeitos do treinamento se mantiveram em longo prazo.

Posteriormente, estudo realizado investigou a aplicação do ultrassom no treinamento de seis japoneses adultos aprendendo inglês como L2. Foram conduzidas quatro sessões de instrução explícita. $\mathrm{O}$ foco se deu, igualmente, nos segmentos $/ \mathrm{l} / \mathrm{e} / \mathrm{I} /$, os quais não pertencem ao inventário fonológico do japonês, o que comumente resulta em dificuldades na produção dessas consoantes por parte dos aprendizes. $\mathrm{O}$ trabalho demonstrou que falantes nativos de japonês obtiveram melhorias na precisão de suas produções dos sons alvos, mantendo os ganhos adquiridos por meio dos treinamentos (TSUI, 2012).

Partindo-se do pressuposto de que, no Brasil, o segmento rótico retroflexo somente ocorre em algumas poucas regiões, e que, nas demais partes do país, falantes não produzem o referido som, acredita-se que alunos brasileiros de inglês como L2 possam, igualmente, beneficiar-se da ferramenta na aquisição desse segmento, haja vista a complexidade que a sua produção implica.

Wilson (2014) assinala outro conjunto de sons a partir dos quais falantes de japonês podem ser assistidos por meio do uso do ultrassom. São eles os pares de vogais: tenso e frouxo (tense and lax) do inglês, como 
por exemplo, as vogais /i/ e /I/ (heat; hit), ou /u/ e /U/ (Luke; look). "Não somente o corpo da língua é um pouco mais baixo nas vogais frouxas, mas a sua raiz também não é avançada para frente como nas vogais tensas" (WILSON, 2014). Em virtude da inexistência desses contrastes no inventário fonológico do português brasileiro, estudos futuros poderão investigar se o auxílio da ferramenta é, de fato, eficaz na aquisição dessas vogais por falantes/aprendizes brasileiros de inglês como L2.

Em suma, visto que determinados segmentos apresentam características que os tornam de difícil aquisição, o acesso a imagens de movimentos articulatórios em tempo real, por meio da ultrassonografia, emerge como potencial mecanismo aos estudos de aquisição em L2, dados os benefícios já mencionados.

\section{Metodologia}

A metodologia empregada pode ser dividia em quatro etapas fundamentais: 1) construção do instrumento de coleta e seleção de sujeitos; 2) coletas pré-teste; 3) duas sessões de instrução explícita com o sujeito em nível básico e, ao final, coletas pós-testes; 4) descrição e análise dos dados. Segue-se, assim, uma melhor descrição de cada uma delas.

Foram selecionados dois sujeitos femininos aprendizes de inglês como língua estrangeira - nível básico e nível avançado. $O$ sujeito do nível básico nunca participou de cursos especializados de língua estrangeira. A informante é estudante universitária, natural de Dom Feleciano-RS - residente em Pelotas-RS há quatro anos -, com idade de 20 anos. Apresenta um baixo índice de massa corporal, o que, conforme Stone (2005), auxilia na visualização do contorno da língua nas imagens captadas pelo aparelho de ultrassom. A informante de nível avançado, igualmente estudante universitária e com idade de 21 anos, é pelotense e estava finalizando curso de Licenciatura em Letras Português/Inglês, tendo realizado, ainda, curso de inglês em Escola de Línguas durante quatro anos.

As produções de róticos realizadas pelo sujeito de nível básico, tendo em vista análise prévia de outiva, constituem-se na fricativa, em palavras como "ca[x]o" e "[x]ato", e no tap, em palavras como "pa[r]e" e "ma[r]". O segmento retroflexo, portanto, não foi detectado em suas produções relativas ao português, o que já era esperado, tendo em vista as 
variantes empregadas em Dom Feliciano e Pelotas. Para a informante de nível avançado, foram detectadas as mesmas variantes.

Para a realização das coletas, em todas as etapas, foram utilizados: gravador digital, modelo Zoom H4N; aparelho de ultrassom Mindray DP6600, com sonda endocavitária - 65EC10EA - acoplada; capacete para limitar os movimentos da sonda, projetado pela Articulate Instruments; sincronizador de áudio e imagem Sync Bright Up modelo SBU 1.0; placa de vídeo, responsável pela ligação entre o ultrassom e o computador, e o software Articulate Assistant Advanced (AAA) ${ }^{54}$, versão 2.14, para coleta e análise dos dados articulatórios, conforme disposto na Figura 1.
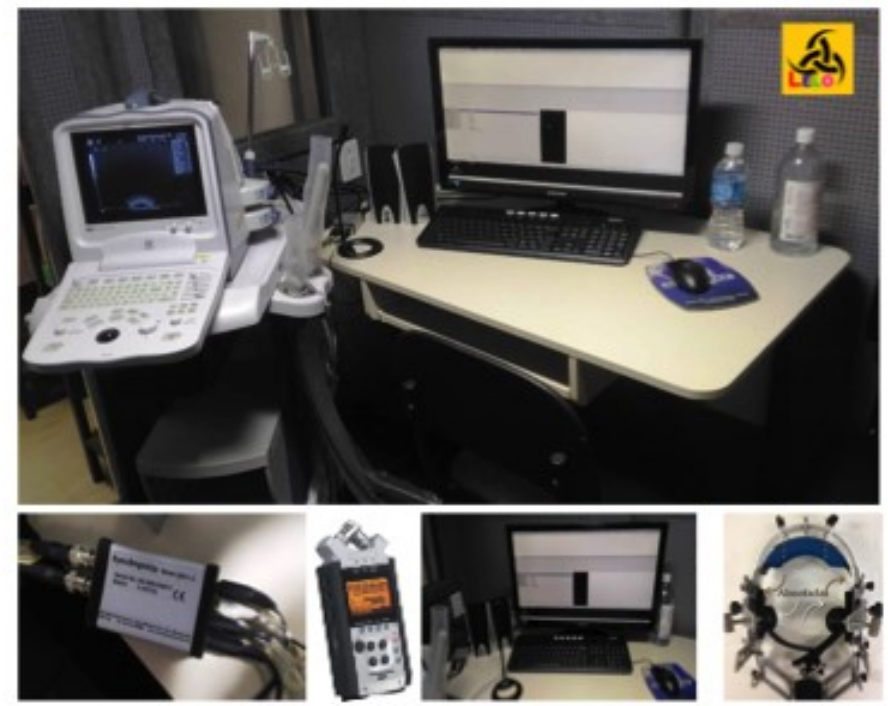

Figura 1: Equipamentos utilizados para as coletas de pré-teste e de pós-testes

Os dados foram coletados em uma cabine de isolamento acústico, localizada no Laboratório Emergência da Linguagem Oral (LELO) da Universidade Federal de Pelotas. As sessões de instrução explícita também ocorreram no laboratório, com a utilização de um ultrassom modelo

${ }^{54}$ AAA - Articulate Assistant Advanced:

http://www.articulateinstruments.com/aaa/ 
Chison Eco1-Vet e de uma sonda micro-convexa MC6-A. Para análise acústica, foi utilizado o software Praat ${ }^{55}$ (versão 6.0.20).

As coletas ocorreram em três etapas: pré-teste, pós-teste 1 e pósteste 2. Havia, ainda, a previsão de realização de um teste de retenção, o qual, pela proximidade do final do semestre, não foi aplicado. Primeiramente, foi realizada a coleta pré-teste, para comparação futura entre as produções iniciais do retroflexo e as produções após as sessões de instrução explícita. Para esta etapa, assim como para as subsequentes, uma lista de nove palavras, em português e inglês, foi elaborada, como pode ser visualizado no Quadro 1.

Quadro 1: Palavras utilizadas para a coleta de dados em cada etapa da pesquisa (pré-teste e pós-testes 1 e 2 )

\begin{tabular}{|c|c|c|}
\hline Posição na palavra & Inglês & Português \\
\hline onset inicial & rabbit & - \\
\hline onset medial & interaction & barata \\
\hline onset complexo & traffic & trave \\
\hline coda medial & apartment & carta \\
\hline coda final & car & mar \\
\hline
\end{tabular}

A distribuição das palavras ocorria por contextos relativos à posição do segmento na sílaba e na palavra - onset inicial, medial e complexo e coda medial e final. $\mathrm{O}$ rótico estava sempre em posição tônica e seguido pela vogal baixa. $O$ contexto consonantal anterior e seguinte era constituído por segmentos plosivos surdos, de forma a facilitar o recorte acústico do rótico.

As palavras em inglês foram produzidas na frase-veículo "I say to you"; já as palavras em português, na frase-veículo "Digo para você”. Houve cinco repetições de cada palavra, sendo que os itens lexicais eram apresentados de forma aleatória à informante.

$\mathrm{Na}$ etapa pré-teste, o sujeito deveria produzir as palavras sem que nenhuma instrução - acerca da produção do rótico - fosse dada previamente. As etapas seguintes, pós-teste 1 e pós-teste 2, ocorreram imediatamente após cada sessão de instrução explícita realizada por um professor de inglês.

${ }^{55}$ Praat - http://www.fon.hum.uva.nl/praat/ 
Deste modo, ao produzir as palavras do instrumento, o sujeito fornecia tanto dados acústicos - captados pelo gravador digital - quanto articulatórios - captados pelo ultrassom e pelo software AAA, responsável pelo registro das imagens ultrassonográficas. Por fim, foi realizada uma sincronização dos áudios com as imagens ultrassonográficas, com uma taxa de $59.600 \mathrm{fps}$.

Importante mencionar também que, antes do início de cada coleta, algumas configurações do ultrassom eram ajustadas, conforme sugerido em Ferreira-Gonçalves e Brum-de-Paula (2013), como Depth para ajustes relativos à profundidade do feixe ultrassonográfico; Gain para ganhos na qualidade da imagem; posição do foco e IP - quanto maior o valor, menor o contraste e melhor a suavização da imagem.

A instrução explícita, a qual ocorria semanalmente, antes de cada pós-teste, era realizada em três etapas. Primeiramente, o professor apresentava, por meio de imagens ultrassonográficas - fotos e vídeos -, o detalhamento articulatório envolvido na produção do segmento retroflexo do inglês. Os vídeos e as imagens eram mostrados de forma reiterada ao informante, acrescidos de explicações do professor acerca dos movimentos articulatórios. Na sequência, com a utilização de um ultrassom, o professor reproduzia os movimentos articulatórios, produzindo isoladamente o som do rótico retroflexo de forma silenciosa para que o aprendiz pudesse manter seu foco apenas nos movimentos articulatórios realizados - e de forma audível, tanto na posição coronal quanto sagital. Por fim, produzia 10 (dez) palavras selecionadas para a instrução em andamento, conforme Quadros 2 e 3. As produções do rótico de forma isolada ou dentro da palavra também eram repetidas três vezes pelo professor. Esta etapa da instrução explícita tinha duração aproximada de 10 minutos.

Quadro 2: Palavras utilizadas durante a primeira sessão de instrução explícita

\begin{tabular}{|c|c|c|}
\hline Posição na palavra & \multicolumn{2}{|c|}{ Palavras } \\
\hline onset inicial & right & rat \\
\hline onset medial & configuration & direction \\
\hline onset complexo & grave & cry \\
\hline coda medial & universal & important \\
\hline coda final & war & your \\
\hline
\end{tabular}


Aquisição do rótico retroflexo do inglês: instrução explícita por meio de ultrassonografia | 137

Quadro 3: Palavras utilizadas durante a segunda sessão de instrução explícita

\begin{tabular}{|c|c|c|}
\hline Posição na palavra & \multicolumn{2}{|c|}{ Palavras } \\
\hline onset inicial & rule & rescue \\
\hline onset medial & ironic & arena \\
\hline onset complexo & drive & trace \\
\hline coda medial & emergency & internal \\
\hline coda final & wear & fur \\
\hline
\end{tabular}

Em uma segunda etapa, com duração aproximada de 25 minutos, o aprendiz realizava exercícios de produção do rótico, também utilizando o aparelho de ultrassom, para que pudesse visualizar, em tempo real, os movimentos articulatórios realizados durante as suas produções. $\mathrm{O}$ segmento retroflexo era produzido com e sem sonoridade e, logo após, inserido na mesma lista de palavras lidas pelo professor durante a primeira etapa. Tais exercícios eram repetidos três vezes pelo aprendiz.

A terceira etapa consistia em uma nova mediação do professor, seguindo exatamente todos os passos realizados na primeira etapa.

Para a análise dos dados ultrassonográficos, foi selecionado, de cada token, o frame que apresentava o ápice do movimento articulatório na produção do rótico, para que pudessem ser traçadas as splines no software AAA.

\section{Resultados e discussão}

Em relação à análise acústica, a partir da obtenção dos dados do sujeito após as três sessões de gravação - pré-teste, pós-teste 1 e pós-teste 2 -, foram considerados os valores de duração absoluta e relativa de cada rótico produzido, a afim de estabelecer comparações entre os resultados dos dois pós-testes com os do pré-teste, coleta na qual o sujeito ainda não havia sido exposto às sessões de instrução explícita. Desta maneira, esperou-se evidenciar a eficácia das sessões de instrução, observando-se 
quais róticos, produzidos como tap ou como vibrante múltipla ${ }^{56}$, passaram a apresentar características de uma retroflexa.

Barbosa \& Madureira (2015) destacam a variedade de produção dos róticos nas línguas do mundo e apontam como principais integrantes deste grupo de consoantes as variantes tap e retroflexa, sendo que a primeira é a mais utilizada pelos brasileiros. Na região de Pelotas - RS e na região de Dom Feliciano, onde foi realizada a pesquisa, ainda figura o tap, com valores de duração consideravelmente menores do que os da vibrante múltipla ${ }^{57}$. Considerando que a produção de um tap corresponde a uma batida rápida da ponta ou lâmina da língua na parte anterior do palato (BARBOSA \& MADUREIRA, 2015), espera-se que uma produção como tap apresente valores de duração relativamente curtos, variando entre 15 e 25 milisegundos (ms).

Já na produção do rótico retroflexo, não há um consenso exato sobre seus valores de duração, os quais estão imbricados aos valores formânticos e de duração da vogal que acompanha o rótico, no entanto, há um considerável alongamento em sua produção, quando comparado à produção de um tap.

Os valores de duração absoluta e relativa obtidos com a análise das produções do sujeito foram ao encontro das características descritas por Barbosa \& Madeira (2015), como pode ser visualizado no Quadro 4.

Quadro 4: Médias das durações relativa e absoluta dos róticos nas coletas pré-teste, pós-teste 1 e pós-teste 2

\begin{tabular}{|c|c|c|c|c|c|c|}
\hline Palavra & $\begin{array}{c}\text { Duração } \\
\text { Absoluta } \\
\text { Pré-teste }\end{array}$ & $\begin{array}{c}\text { Duração } \\
\text { relativa } \\
\text { pré-teste }\end{array}$ & $\begin{array}{c}\text { Duração } \\
\text { absoluta } \\
\text { pós-teste 1 }\end{array}$ & $\begin{array}{c}\text { Duração } \\
\text { relativa } \\
\text { pós-teste 1 }\end{array}$ & $\begin{array}{c}\text { Duração } \\
\text { absoluta } \\
\text { pós-teste 2 }\end{array}$ & $\begin{array}{c}\text { Duração } \\
\text { relativa } \\
\text { pós-teste 2 }\end{array}$ \\
\hline barata & $21 \mathrm{~ms}$ & $3,55 \%$ & $30 \mathrm{~ms}$ & $5,21 \%$ & $24 \mathrm{~ms}$ & $4,01 \%$ \\
\hline interaction & $27 \mathrm{~ms}$ & $3,01 \%$ & $104 \mathrm{~ms}$ & $10,66 \%$ & $104 \mathrm{~ms}$ & $11,32 \%$ \\
\hline carta & $61 \mathrm{~ms}$ & $12,66 \%$ & $66 \mathrm{~ms}$ & $15,53 \%$ & $56 \mathrm{~ms}$ & $12,45 \%$ \\
\hline apartment & $41 \mathrm{~ms}$ & $4,26 \%$ & $140 \mathrm{~ms}$ & $15,91 \%$ & $110 \mathrm{~ms}$ & $12,17 \%$ \\
\hline mar & $95 \mathrm{~ms}$ & $18,15 \%$ & $72 \mathrm{~ms}$ & $17,21 \%$ & $70 \mathrm{~ms}$ & $16,93 \%$ \\
\hline
\end{tabular}

${ }^{56}$ Apesar do predomínio do tap nas produções da informante, no que concerne às palavras em língua portuguesa, a análise acústica constatou a realização da vibrante múltipla, principalmente em posição de coda.

57 Para uma análise articulatória do rótico produzido por falantes pelotenses, ver Melcheque, Ferreira-Gonçalves e Brum-de-Paula (2018). 
Aquisição do rótico retroflexo do inglês: instrução explícita por meio de ultrassonografia | 139

\begin{tabular}{|c|c|c|c|c|c|c|}
\hline car & $91 \mathrm{~ms}$ & $22,89 \%$ & $174 \mathrm{~ms}$ & $44,57 \%$ & $161 \mathrm{~ms}$ & $40,73 \%$ \\
\hline trave & $45 \mathrm{~ms}$ & $7,18 \%$ & $25 \mathrm{~ms}$ & $5,40 \%$ & $23 \mathrm{~ms}$ & $4,59 \%$ \\
\hline traffic & $28 \mathrm{~ms}$ & $4,72 \%$ & $55 \mathrm{~ms}$ & $10,96 \%$ & $57 \mathrm{~ms}$ & $11,21 \%$ \\
\hline rabbit & $79 \mathrm{~ms}$ & $12,72 \%$ & $118 \mathrm{~ms}$ & $18,03 \%$ & $97 \mathrm{~ms}$ & $15,45 \%$ \\
\hline
\end{tabular}

Como é possível observar, houve um aumento expressivo nos valores de duração relativa e absoluta do segmento retroflexo em todos os contextos silábicos. Alguns valores, como em posição de onset medial e coda medial, triplicaram em relação aos valores constatados no pré-teste, já na primeira sessão do pós-teste, e se mantiveram na segunda sessão: interaction, de $3,01 \%$ para $10,66 \%$ e $11,32 \%$; apartment, de $4,26 \%$ para $15,91 \%$ e 12,17\%. Em coda final, podem-se constatar diferenças expressivas quando são comparados o par mar e car. Os valores de duração relativa são aproximados no pré-teste, $18,15 \%$ e $22,89 \%$, no entanto, distanciam-se nos pós-testes 1 e 2, 17,21\% e 44,57\%, e 16,93\% e 40,73\%. Em onset complexo, o padrão de diferenças permanece, pois, no par trave e traffic, os valores de duração relativa aproximados do pré-teste se distanciam expressivamente nas coletas pós-teste. Já nas palavras em português, os róticos mantiveram valores aproximados nas três coletas realizadas, apresentando diferenças apenas quando comparados em relação a diferentes posições silábicas.

Em relação à posição de coda medial, observam-se valores de duração relativa elevados para as médias do rótico do português nas três coletas realizadas. Tais valores se justificam porque, nesse contexto, a informante produz, na verdade, uma vibrante múltipla.

O efeito da instrução explícita, por meio da ultrassonografia, revela-se, pois, expressivo nas análises acústicas realizadas. Em onset medial, considerando-se o par barata e interaction, por exemplo, na coleta pré-teste, os valores de duração relativa dos róticos eram muito aproximados, 3,55\% e 3,01\%, respectivamente; no pós-teste 1 , no entanto, os valores já são bastante díspares, com 5,21\% e 10,66\%.

Os resultados acústicos, ainda que relativos a um estudo de caso, revelam a precisão e eficácia da ferramenta, sinalizando para uma promissora aquisição de segmentos em um curto período de tempo. $\mathrm{O}$ diferencial parece estar no efeito do contato direto - em tempo real - que o aluno passa a ter com sua a produção, um contato visual e acústico.

As imagens nas Figuras 2 e 3 evidenciam as diferenças entre as produções do alvo retroflexo no pré-teste e no pós-teste 1 , nas quais as 
140 | Giovana Ferreira-Gonçalves, Otávio Tadeu Alves Pereira e Misael Krüger Lemes

setas brancas indicam a ponta da língua.

Figura 2 - Imagens ultrassonográficas da produção do rótico em apartment nas coletas pré-teste (esquerda) e pós-teste 1 (direita)

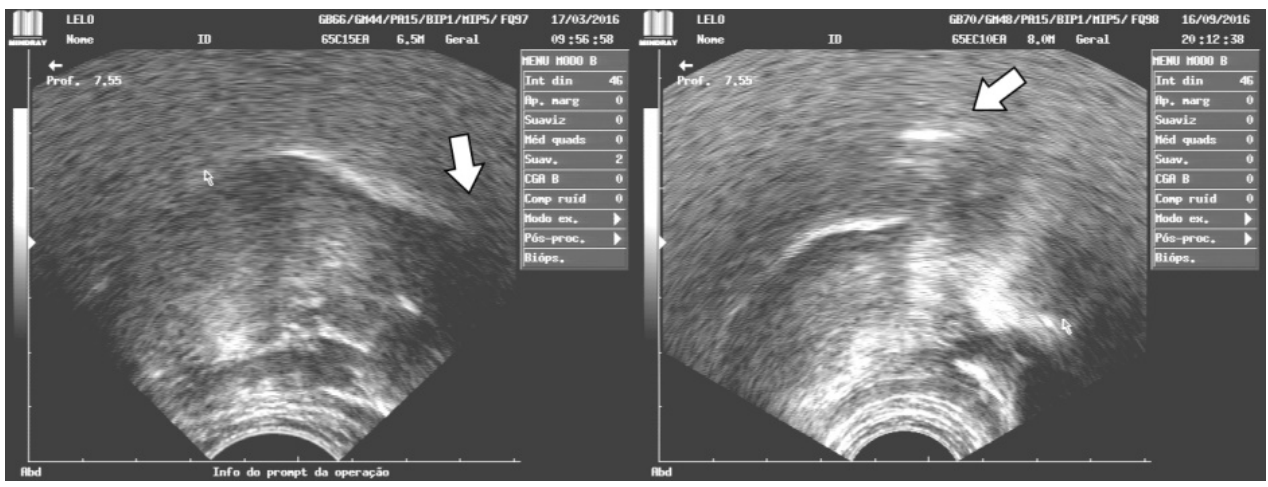

Figura 3 - Imagens ultrassonográficas da produção do rótico em traffic nas coletas pré-teste (esquerda) e pós-teste 1 (direita)

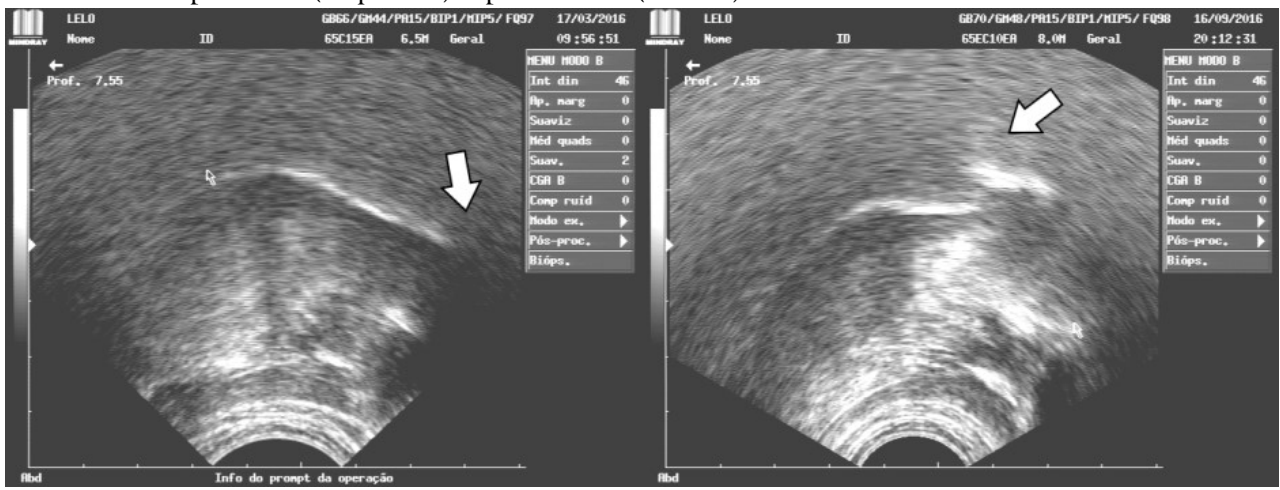

Conforme pode ser visualizado nas Figuras 2 e 3, é evidente a aquisição do movimento retroflexo na produção dos róticos, os quais anteriormente eram produzidos como tap: a ponta da língua, que geralmente não se mostra aparente nas imagens ultrassonográficas na produção do tap, acha-se visível e com o encurvamento característico da variante retroflexa. A retração do corpo da língua também pode ser observada. Esses movimentos são encontrados em todas as produções 
realizadas pelo sujeito nas sessões pós-teste 1 e 2 , o que caracteriza o rápido ganho articulatório proporcionado pelas instruções.

Os dados articulatórios do sujeito de nível básico, gerados pelo software de análise AAA, demonstram um ganho gestual em todos os contextos silábicos, o que corrobora os dados acústicos, mesmo no caso menos expressivo acusticamente, em onset inicial.

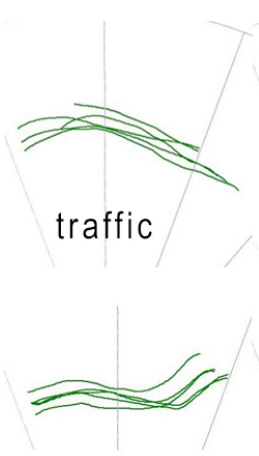

traffic

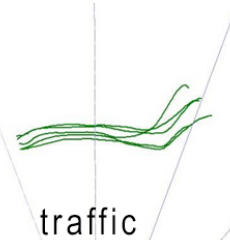

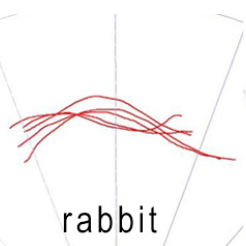

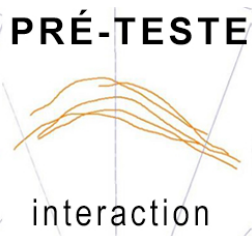

\section{PÓS-TESTE 1}

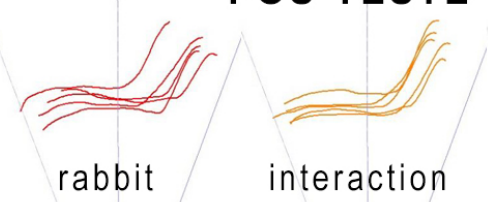

\section{PÓS-TESTE 2}

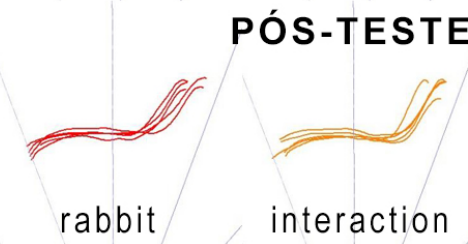

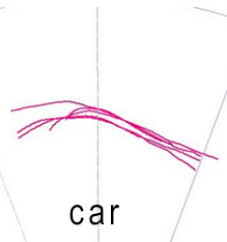

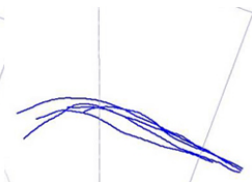

apartment
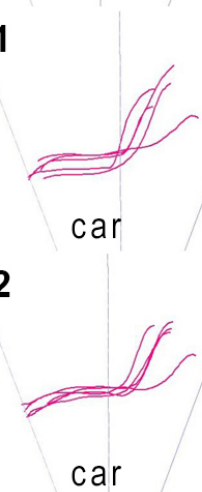

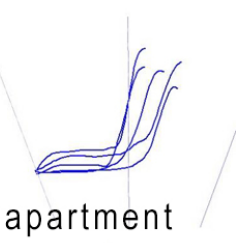

apartment

Figura 4: Splines geradas pelo software AAA a partir dos dados articulatórios da aprendiz de nível básico

Já os dados articulatórios da informante de nível avançado demonstraram inconsistência na produção do rótico. O sujeito, nos contextos silábicos onset inicial, onset complexo e onset medial, produz a variante retroflexa; já nos contextos de coda medial e final, produz o que Thomas (2011), entre outros, identifica como um rótico do tipo bunched. Essa variação apresenta uma retração na parte central da língua, mas mantém a ponta em uma posição mais anterior e com pouco movimento retroflexo. Westbury et al (1998, apud Thomas, 2011), afirma que a produção deste rótico, principalmente nos Estados Unidos, está em um 
contínuo de articulação, sendo ora produzido como retroflexa, ora como bunched. Nota ainda que este processo pode ser verificado com frequência em um mesmo falante. Segundo Thomas (2011), é possível estabelecer essa diferença a partir da relação entre F4 e F5, os quais se apresentam mais distantes na variante retroflexa e mais próximos na variante bunched.

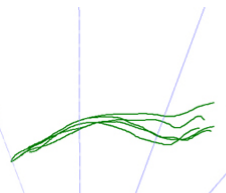

traffic

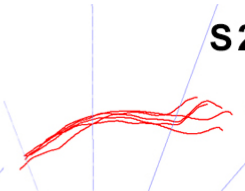

rabbit
S2 - AVANÇADO

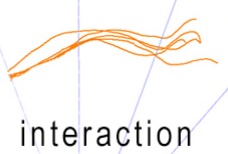

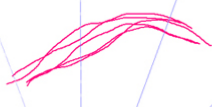

car

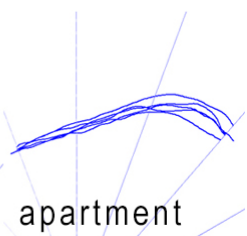

Figura 5: Splines geradas pelo software AAA a partir dos dados articulatórios da informante de nível avançado

\section{Conclusão}

O uso do ultrassom na realização de tarefas de instrução explícita voltadas para a aquisição de segmentos é ainda, como se observou, incipiente no Brasil e no exterior. Há poucos estudos e descrições sobre a utilização da ultrassografia nos estudos em L2, sobre a construção de instrumentos de coleta e de tarefas de ensino que propiciem aos estudantes de uma segunda língua o contato direto com sua produção, com seus movimentos articulatórios.

Nos dados aqui analisados, a instrução explícita, por meio da ultrassonografia, foi fator determinante para a aquisição precoce do segmento retroflexo. Com a mediação de um professor e com acesso aos próprios movimentos articulatórios sendo executados em tempo real, o aluno pôde ser guiado para uma realização mais adequada dos movimentos articulatórios na produção do segmento retroflexo, o que conduz à aquisição mais rápida do segmento alvo.

Considerando-se o baixo número de sujeitos da presente pesquisa, para a sedimentação dos resultados, os próximos passos da pesquisa envolvem a inclusão de um maior número de sujeitos e a realização de um teste de retenção. 


\section{REFERÊNCIAS}

ABEL, J.; ALLEN, B.; BURTON, S.; KAZAMA, M.; KIM, B.; NOGUCHI, M.; TSUDA, A.; YAMANE, N.; GICK, B. Ultrasoundenhanced multimodal approaches to pronunciation teaching and learning. Canadian Acoustics, v. 43, n. 3, 2015.

ALVES, U. O papel da instrução explícita na aquisição fonológica do inglês como L2: evidências fornecidas pela teoria da otimidade. Pelotas, UCPEL, 2004. Dissertação de Mestrado, Pós-graduação em Letras, Universidade Católica de Pelotas.

BARBOSA, P. A; MADUREIRA, S. Sons "R". In: Manual de fonética acústica experimental: aplicações a dados do português. São Paulo: Cortez, 2015. p. 535 - 568.

BLISS, $\mathrm{H}$. et al. Using Multimedia Resources to Integrate Ultrasound Visualization for Pronunciation Instruction into Postsecondary Language Classes. Journal of Linguistics and Language Teaching, v. 8, n. 2, p. 173-188, 2017

CAVAlHEIRO, B. S. D. Aquisição da vogal [a] espnahola por falantes de português brasileiro. Pelotas, UFPEL, 2016. Dissertação de Mestrado, Pós-graduação em Letras, Universidade Federal de Pelotas.

CELCE-MURCIA, M. et al. Teaching Pronunciation: a course book and reference guide. 2nd. ed. New York: Cambridge University Press, 2010.

FERREIRA-GONÇALVES, G.; BRUM-DE-PAULA, M. R. Dinâmica dos movimentos articulatórios: sons, gestos e imagens. Pelotas: Editora UFPel, 2013.

GARCIA, L.S.; FERREIRA-GONÇALVES, G. Instrução explícita por meio da ultrassonografia: uma nova ferramenta para a aquisição da lateral /1/ do espanhol. In: SOUSA, A. M.; GARCIA, R.; SANTOS, T.C. Perspectivas para o ensino de linguas, v.3, Rio Branco: EDUFAC, 2019.

GICK, B.; BERNHARDT, B.; BACSFALVI, P.; WILSON, I. Ultrasound imaging applications in second language acquisition. In: EDWARDS, J.; ZAMPINI, M (eds) Phonology and Second Language Acquisition. Amsterdam: John Benhamins, 2008.

LEMES, M. K.; DUARTE, N. M.; FERREIRA-GONÇALVES, G. A ultrassonografia aplicada à aquisição do segmento retroflexo em 
inglês. Trabalho apresentado no Workshop em estudos ultrassonográficos de dados de fala, 21o InPLA, PUC-SP, 2018.

LOOSE, R. E. O papel da instrução explícita na aquisição/aprendizagem de estruturas do espanhol por falantes do Português. 2006. 119 f. Dissertação (Mestrado em Letras) - Escola de Educação, Universidade Católica de Pelotas, Pelotas, 2006.

MACEDO, M. H. O papel da instrução explícita na aquisição dos padrões de vozeamento final do inglês por aprendizes brasileiros. Pelotas, UCPel, 2011. Dissertação de Mestrado, Pós-graduação em Letras, Universidade Católica de Pelotas.

MELCHEQUE, P.P.; FERREIRA-GONÇALVES, G.; BRUM-DEPAULA, M. A configuração gestual do rótico no dialeto pelotense. Trabalho apresentado no Workshop em estudos ultrassonográficos de dados de fala, 21o InPLA, PUC-SP, 2018.

PEROZZO, R. V. Percepção de oclusivas não vozeadas sem soltura audivel em codas final do inglês (L2) por brasileiros: o papel do contexto fonéticofonológico, da instrução explícita e do nivel de proficiência. Porto Alegre, UFRGS, 2013. Dissertação de Mestrado, Pós-graduação em Letras, Universidade Federal do Rio Grande do Sul.

STONE, M. A guide to analyzing tongue motion from ultrasound images. Clinical Linguistics and Phonetics, 19,6/7, 2005;

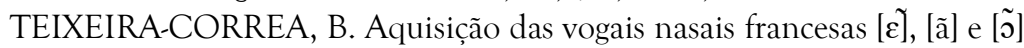
por aprendizes brasileiros: aspectos acústico-articulatórios. Pelotas, UFPEL, 2017. Dissertação de Mestrado, Pós-graduação em Letras, Universidade Federal de Pelotas.

TEIXEIRA-CORREA, B.; FERREIRA-GONÇALVES, G.; BRUM-DEPAULA, M. Aquisição das vogais nasais francesas [ع], [ã] e [0] por aprendizes brasileiros: aspectos articulatórios. Ilha do Desterro v. 70, no 3, p. 131-149, 2017.

THOMAS, E. Sociophonetics: an introduction. United Kingdom: Palgrave Macmillan, 2011.

TSUI, H. M. L. Ultrasound speech training for Japanese adults learning English as second language. Doctoral Dissertation. Canada: The University of British Columbia, 2012.

ZIMMER, M. C.; ALVES, U. K. A produção de aspectos fonéticofonológicos da segunda língua: instrução explícita e conexionismo. Revista Linguagem Ë Ensino, v. 9, n. 2, p. 101-143, 2006. 
WILSON, I. Using ultrasound for teaching and researching articulation. Acoustical Science and Technology, v. 35, n. 6, p. 285-289, 2014.

WILSON, I., GICK, B. Ultrasound Technology and Second Language Acquisition Research. In: Mary Grantham O’Brien, Christine Shea and John Archibald (eds). Proceedings of the 8th Generative Approaches to Second Language Acquisition Conference (GASLA). Somerville, MA: Cascadilla Proceedings Project, p.148- 152, 2006.

Recebido em: 31/01/2019

Aceito em: 15/02/2019 